\title{
Amazon Forest Radiation Budget from Satellite Data
}

\author{
J.-C. Calvet AND Y. Viswanadham \\ Instituto Nacional de Pesquisas Espaciais, São José dos Campos, Brazil
}

(Manuscript received 9 April 1992, in final form 31 August 1992)

ABSTRACT

\begin{abstract}
The top-of-the-atmosphere net radiation is determined over the Ducke Reserve Forest site, Manaus, Brazil $\left(2^{\circ} 57 \mathrm{~S}, 59^{\circ} 57 \mathrm{~W}\right)$, from GOES-7 visible and infrared data during the 1.987 wet season (April-May), for 0900 and 1500 LST. It is shown that a very good correlation exists between the top-of-the-atmosphere net radiation and the net radiation measured at the surface.
\end{abstract}

\section{Introduction}

The determination of the Amazon forest water vapor, carbon dioxide, and heat emission is an important issue for global climatic change studies. The exchange of energy between the surface and the atmosphere is driven by the surface net radiation. In the case of the Amazon forest, the use of satellite data is highly desirable since there is no routine measurement of the surface net radiation.

Recently, a number of authors have investigated techniques to derive the surface radiation budget from top-of-the-atmosphere radiation budget components as determined from Geostationary Operational Environmental Satellites (GOES). For example, Pinker and Tarpley (1988) have conducted a study over Canada showing that the daily averaged planetary net radiation is very well correlated with the daily average surface net radiation.

In this study, the relationship between the planetary and surface net radiation is investigated over the Amazon forest, at 0900 and 1500 LST. The planetary net radiation is estimated from the GOES visible band and infrared (IR) window radiance. The surface net radiation was measured at the Ducke Reserve Forest, Manaus, Brazil (DRF) (Viswanadham et al. 1990).

\section{Data \\ a. Satellite data}

During the wet season (April-May) of 1987, GOES-7 visible and IR images over the region of Manaus $\left(3^{\circ} \mathrm{S}, 60^{\circ} \mathrm{W}\right)$, Amazonas, Brazil, were recorded at Instituto Nacional de Pesquisas Espaciais (INPE) as part

Corresponding author address: Jean-Christophe Calvet, Meteo France, CNRM/GMME/MAI, 42, Av. Coriolis, 31057, Toulouse, Cedex, France. of the Global Tropospheric Experiment (GTE)-Amazon Boundary Layer Experiment (ABLE)-2B mission (Harriss et al. 1990). The data consist of $1-\mathrm{km} \times 1$ $\mathrm{km}$ resolution visible $(0.55-0.75 \mu \mathrm{m})$ and $8 . \mathrm{km} \times 4-$ $\mathrm{km}$ resolution IR (10.2-12.2 $\mu \mathrm{m})$ pixels. After an approximate navigation, they were selected and stored as maps of about $50 \mathrm{~km}$ on a side. Theoretically, the central pixel covers the DRF site. Two sets of maps covering the site of DRF are available, at 1300 and 1900 UTC, thus 0900 and 1500 LST at DRF.

As a first step, the navigation procedure (Hambrick and Philips 1980) was applied without using any landmark. A few-IR-pixels error is thus likely to occur. In section 3 a method is developed to improve the precision of the navigation.

\section{b. Surface data}

The surface data consist of 20 minutes averaged net radiation, at 0900 and 1500 LST, measured at the top of the 45-m tower installed at DRF (Viswanadham et al. 1990). A Funk-type net radiometer was used whose estimated error is $3 \%$ or less. This radiometer has been used and recalibrated over 10 years with a total change in calibration of about $1 \%$ over this time.

\section{Method and results}

\section{a. IR pixels treatment}

The IR data processing to obtain flux equivalent temperatures $T_{f}$ consists of four steps: calibration, correction for limb darkening, inversion of the Planck law, and spectral integration.

The calibration, inversion of the Planck law, and spectral integration are obtained using the coefficients given by NOAA (1986). In order to perform limb darkening corrections, the satellite zenith angle $\theta$ is calculated for each IR pixel, and the IR radiance $R(\theta)$, $\left[\mathrm{mW}\left(\mathrm{m}^{2} \mathrm{sr} \mathrm{cm}\right)^{-1}\right]$, is normalized to a central satellite 
zenith radiance $R(0)$ using the empirical equation (Abel and Gruber 1979)

$$
\begin{aligned}
& R(0)=R(\theta)-[2.301-0.04767 R(\theta)]\left(\cos ^{-1} \theta-1\right) \\
& \quad+[0.1244-0.002096 R(\theta)]\left(\cos ^{-1} \theta-1\right)^{2} .
\end{aligned}
$$

\section{b. Visible pixels treatment}

Three steps are required to determine the pixel planetary albedo $A_{p}$ from the digital count: determination of the directional narrowband reflectance $r_{g}$, spectral integration, and angular integration. The parameter $r_{g}$ is determined for each pixel using calibration coefficients given by Frouin and Gautier (1987) for GOES-6, as

$$
r_{g}=\frac{1.632 \times 10^{-3}\left(\operatorname{count}^{2}\right)-1.0}{307.9 \cos \theta_{0}},
$$

where $\theta_{0}$ is the solar zenith angle. Frouin and Gautier (1987) have derived average postlaunch calibration coefficients for GOES-5 and GOES-6. It is shown that the change in calibration coefficients is lower than the error over each of them. Therefore, it can be assumed that the GOES-6 calibration can be efficiently extended to GOES-7 data.

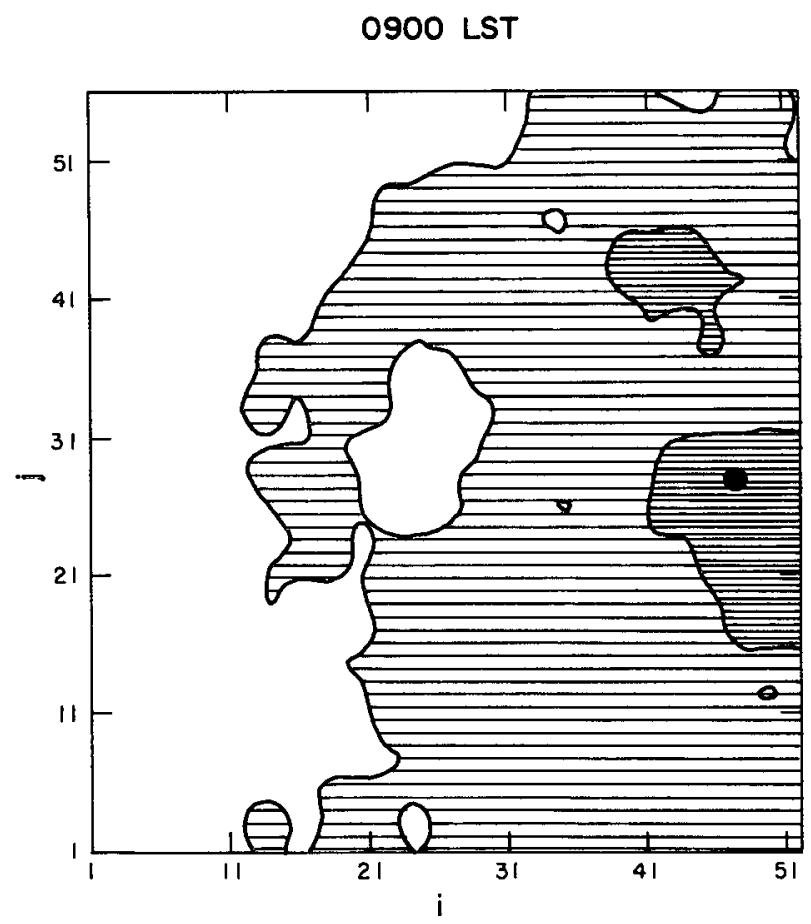

FIG. 1. Map of the square correlation coefficient $r^{2}$ between the GOES planetary net radiation and the DRF net radiation at 0900 LST. Values greater than 0.8 are darkly shaded. Values less than 0.8 and greater than 0.6 are lightly shaded. The dark point indicates the maximum value of $r^{2}\left(r^{2}=0.85\right)$.
1500 LST

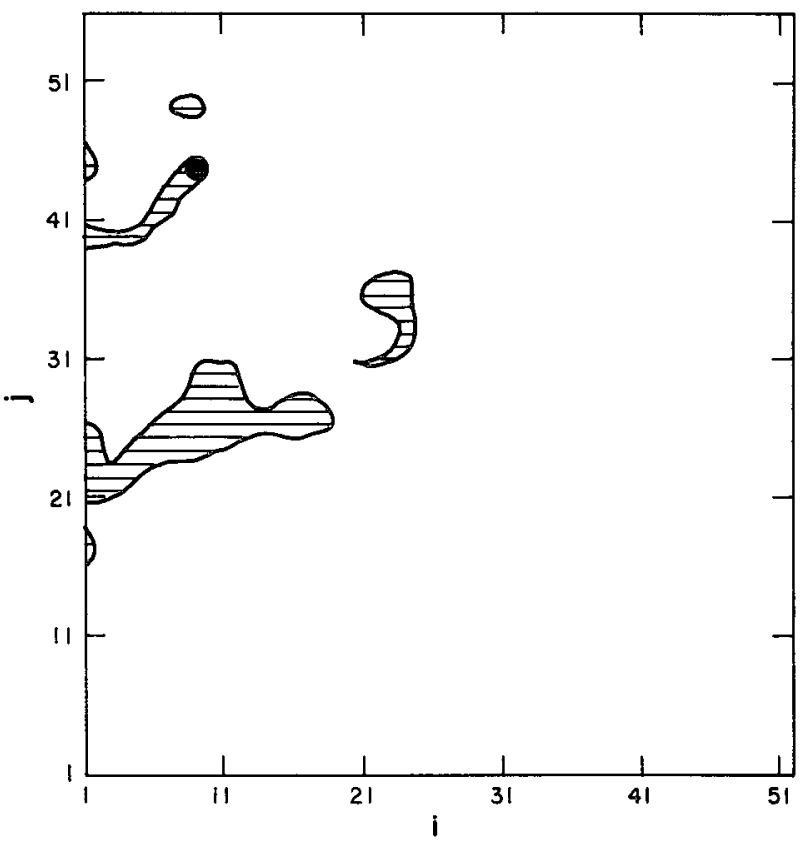

FIG. 2. As in Fig. 1 except for 1500 LST.

The maximum value is $r^{2}=0.85$.

Spectral and angular integration are performed using the regression coefficients given by Smith et al. (1981) for GOES-1. Pinker et al. (1986) have addressed the applicability of this calibration to GOES-5. They show that it gives relatively good results. In this study, it is supposed that this calibration can also be applied to GOES-7. The choice of the coefficients depends on the type of observed surface as far as spectral integration is concerned. Three classes of surfaces are considered: "vegetation," "thin cloud," and "thick cloud." They are defined according to $r_{g}$ and $T_{f}$ thresholds given by Smith et al. (1981).

\section{c. Planetary budget components}

The outgoing planetary longwave flux $L_{W}$ is computed for each pixel. The values of $\mathrm{LW}_{p}$ are calculated from the Stefan-Boltzman equation

$$
\mathrm{LW}_{p}=\sigma T_{f}^{4},
$$

where $\sigma=5.6693 \times 10^{-8} \mathrm{~W} \mathrm{~m}^{-2} \mathrm{~K}^{-4}$ is the Stefan's constant. The all-wave planetary net radiation $\mathrm{RN}_{p}$ is then computed from $\mathrm{LW}_{p}$ and $A_{p}$. It can be written as

$$
\mathrm{RN}_{p}=\left(1-A_{p}\right) \cos \theta_{0} E_{0}-\mathrm{LW}_{p},
$$

where $E_{0}=1353 \mathrm{~W} \mathrm{~m}^{-2}$ is the extraterrestrial solar radiance (Thekaekara 1971 ). 


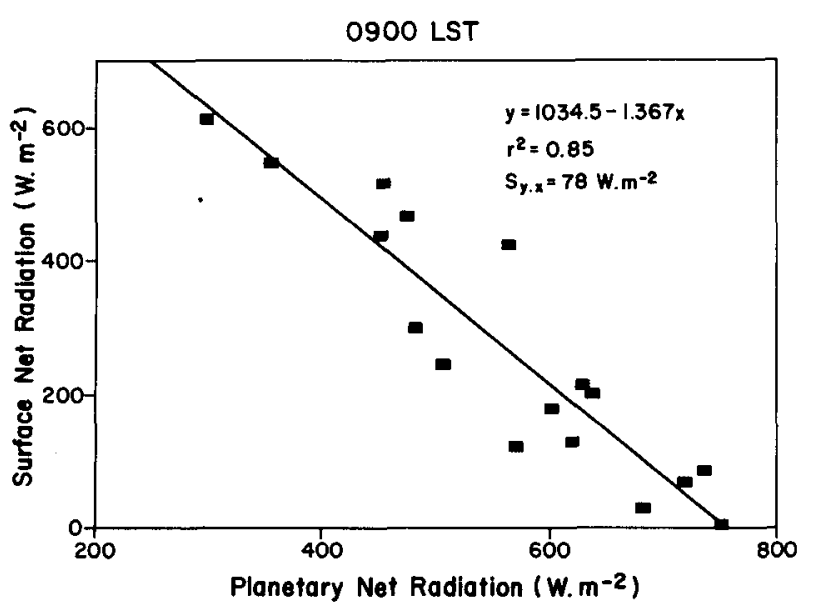

FIG. 3. The DRF net radiation versus the planetary net radiation for 0900 LST.

\section{d. Refined navigation using temporal analysis}

In an attempt to use the DRF tower net radiation measurements as a landmark for navigation, the linear correlation coefficients between $\mathrm{RN}_{s}$ (measured at DRF site) and $\mathrm{RN}_{p}$ were computed for each pixel, at the $1-\mathrm{km} \times 1-\mathrm{km}$ visible resolution. Seventeen and 13 days are available for the 0900 and 1500 LST measurements, respectively.

Figures 1 and 2 show the correlation maps for 0900 and 1500 LST, respectively. In both cases, the DRF 1$\mathrm{km} \times 1-\mathrm{km}$ pixel $(I, J)$ squared correlation coefficient $r^{2}$ is given as $r^{2}(I, J)=\max \left[r^{2}(i, j)\right]$. The $r^{2}$ maximum location differs from one LST to another, for the satellite subpoint traces a distorted figure eight during its 1-day orbital period (Hambrick and Philips 1980).

This refined navigation procedure is valid if the latitude-longitude error is the same amount and in the same direction each day. Considering the short period covered by the data and given the high $r^{2}(I, J)$ peaks

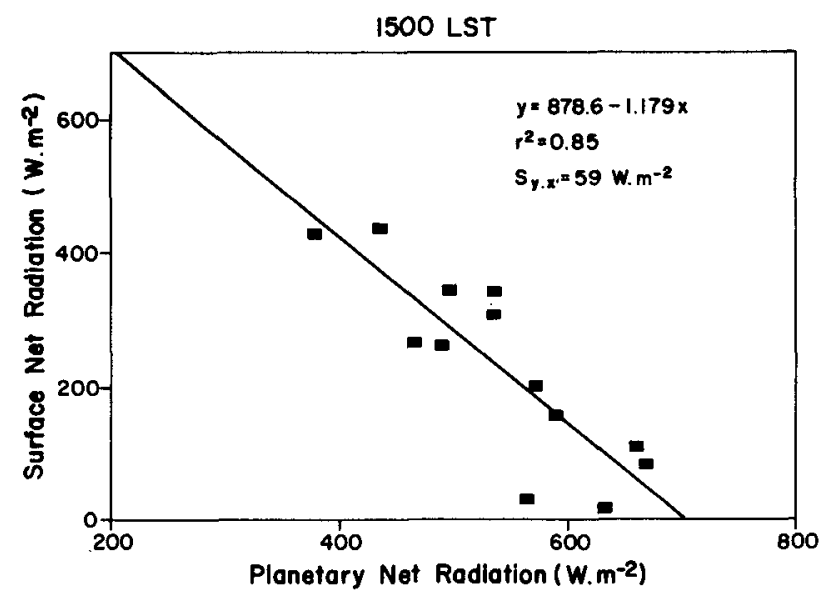

FIG. 4. As in Fig. 3 except for 1500 LST.
TABLE 1. Linear regression statistics between the GOES planetary net radiation $\mathrm{RN}_{p}$ and the DRF net radiation $\mathrm{RN}_{s}$, and between the GOES planetary outgoing longwave flux $\mathrm{LW}_{p}$ and $\mathrm{RN}_{s}$, for 0900 and $1500 \mathrm{LST}$, during the wet season 1987. The standard error of estimate is $S_{y \cdot x}$ and subscript $y \cdot x$ represents the product of $\mathrm{RN}_{s}$ and $\mathrm{RN}_{p}$ (or $\mathrm{RN}_{s}$ and $\mathrm{LW}_{p}$ ).

\begin{tabular}{|c|c|c|c|c|}
\hline \multirow{3}{*}{$\begin{array}{l}\text { Regression } \\
\text { parameters }\end{array}$} & \multicolumn{4}{|c|}{ Independent variables } \\
\hline & \multicolumn{2}{|c|}{$\mathrm{RN}_{p}$} & \multicolumn{2}{|c|}{$\mathrm{LW}_{p}$} \\
\hline & 0900 LST & 1500 LST & 0900 LST & 1500 LST \\
\hline$a\left(\mathrm{~W} \mathrm{~m}^{-2}\right)$ & 1034.5 & 878.6 & -176.5 & -28.0 \\
\hline$b$ & -1.367 & -1.179 & 1.709 & 1.014 \\
\hline$r^{2}$ & 0.85 & 0.85 & 0.79 & 0.72 \\
\hline$S_{y \cdot x}\left(\mathrm{~W} \mathrm{~m}^{-2}\right)$ & 77 & 59 & 92 & 80 \\
\hline
\end{tabular}

(see Figs. 1 and 2), it can be assumed that no maneuver led to significant discontinuities in the orbit and attitude of the satellite.

\section{e. $R N_{p}$ and $L W_{p}$ as predictors of $R N_{s}$}

Figures 3 and 4 show plots of the linear relationship obtained from least-squares regression analysis of 0900 and 1500 LST datasets for which $r^{2}$ is maximum. Table 1 presents the results of the regression analysis of the following equations:

$$
\begin{aligned}
& \mathrm{RN}_{s}=a_{\mathrm{RN}}+b_{\mathrm{RN}} \mathrm{RN}_{p}, \quad \text { and } \\
& \mathrm{RN}_{s}=a_{\mathrm{LW}}+b_{\mathrm{LW}} \mathrm{LW}_{p} .
\end{aligned}
$$

The obtained high correlation coefficients show that the surface net radiation can be indirectly inferred from satellite planetary net radiation or even longwave outgoing radiation alone, without temporal averaging of these parameters. It must be noticed that the correlation between $\mathrm{RN}_{s}$ and $\mathrm{RN}_{p}$ is negative, whereas a positive correlation was found over Toronto, Canada, during the summer season (Pinker and Tarpley 1988). This may be due to different cloud characteristics, which govern the net radiative difference between the top of the atmosphere and the surface (Pinker and Corio 1984; Hartmann and Doelling 1991 ).

\section{Conclusions}

The planetary net radiation calculated from routine GOES data was found to be a good predictor of the surface net radiation over the Amazon forest at 0900 and $1500 \mathrm{LST}$. This result is of particular significance for the determination of the radiation budget of a secluded area like the Amazon forest. It was also shown that a surface measurement of net radiation can be used as a landmark for navigation.

However, additional studies are needed to investigate the spatial dependence of the statistical relationships which can be derived between the top-of-the-atmosphere and the surface net radiation with their diurnal and seasonal evolution. 
Acknowledgments. This work was supported by the French Foreign Affairs Ministry. The authors thank Mr. N. Arai and Dr. N. J. Ferreira for their helpful comments, Dr. A. W. Setzer for providing the satellite data, and Mr. J. L. de Oliveira and Mr. J. L. M. Nogueira for technical assistance.

\section{REFERENCES}

Abel, P., and A. Gruber, 1979: An improved model for calculation of longwave flux at $11 \mu \mathrm{m}$. NOAA Tech. Memo. NESS 106, U.S. Department of Commerce, National Oceanic and Atmospheric Administration, National Environmental Satellite Service, 24 pp. [NTIS PB80-119431.]

Frouin, R., and C. Gautier, 1987: Calibration of NOAA-7 AVHRR, GOES-5, and GOES-6 VISSR/VAS solar channels. Remote Sens. Environ., 22, 73-101.

Hambrick, L. N., and D. R. Phillips, 1980: Earth locating image data of spin-stabilized geosynchroneous satellites. NOAA Tech. Memo. NESS 111, U.S. Department of Commerce, National Oceanic and Atmospheric Administration, National Environmental Satellite Service, 49 pp. [NTIS PB80-120321.]

Harriss, R. C., M. Garstang, S. C. Wofsy, S. M. Beck, R. J. Bendura, J. R. B. Coelho, J. W. Drewry, J. M. Hoell, Jr., P. A. Matson, R. J. McNeal, L. C. B. Molion, R. L. Navarro, V. Rabine, and R. L. Snell, 1990: The Amazon Boundary Layer Experiment: Wet season 1987. J. Geophys. Res., 95, 16 721-16 736.
Hartmann, D. L., and D. Doelling, 1991: On the net radiative effectiveness of clouds. J. Geophys. Res., 96, 869-891.

National Oceanic and Atmospheric Administration, 1986: Operational VAS Mode AAA Format Specification. SFP 002, version 2.3, National Oceanic and Atmospheric Administration, 252 pp. and appendixes.

Pinker, R. T., and L. A. Corio, 1984: Surface radiation budget from satellites. Mon. Wea. Rev., 112, 209-215.

- and J. D. Tarpley, 1988: The relationship between the planetary and surface net radiation: An update. J. Appl. Meteor., 27,957964.

- J. A. Ewing, and A. Gruber, 1986: Diurnal variation of planetary radiation budget parameters from geostationary satellites. $J$. Climatol., 6, 389-403.

Smith, W. L., L. D. Herman, T. Schreiner, H. B. Howell, and P. Menzel, 1981: Radiation budget characteristics of the onset of the summer monsoon. Int. Conf. Early Results of FGGE and Large-Scale Aspects of the Monsoon Experiment. Tallahassee, International Association of Meteorology and Atmospheric Physics/WMO/Amer. Meteor. Soc., 6.16-6.27.

Thekaekara, M. P., 1971: Solar electromagnetic radiation. NASA Space Vehicle Design Criteria, (Environment), NASA SP-8005, $36 \mathrm{pp}$. [NTIS N71-3088 NTIS issue 7100.]

Viswanadham, Y., L. C. B. Molion, A. O. Manzi, L. D. A. Sá, V. P. Silva Filho, R. G. B. André, J. L. M. Nogueira, and R. C. dos Santos, 1990: Micrometeorological measurements in Amazon forest during GTE/ABLE 2A mission. J. Geophys, Res., 95, 13 669-13 682. 